\title{
Changes in political trust in Britain during the COVID-19 pandemic in 2020: integrated public opinion evidence and implications
}

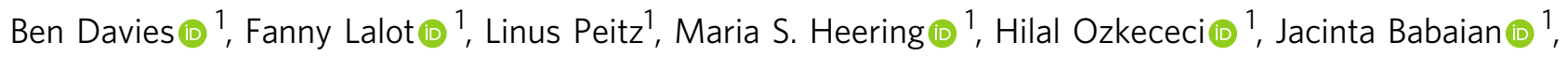
Kaya Davies Hayon (1) ${ }^{2}$, Jo Broadwood (1) ${ }^{2} \&$ Dominic Abrams (i) ${ }^{1 \times}$

In this paper, we document changes in political trust in the UK throughout 2020 so as to consider wider implications for the ongoing handling of the COVID-19 pandemic. We analysed data from 18 survey organisations with measures on political trust (general, leadership, and COVID-19-related) spanning the period December 2019-October 2020. We examined the percentage of trust and distrust across time, identifying where significant changes coincide with national events. Levels of political trust were low following the 2019 UK General Election. They rose at the onset of UK lockdown imposed in March 2020 but showed persistent gradual decline throughout the remainder of the year, falling to pre-COVID levels by October 2020. Inability to sustain the elevated political trust achieved at the onset of the pandemic is likely to have made the management of public confidence and behaviour increasingly challenging, pointing to the need for strategies to sustain trust levels when handling future crises.

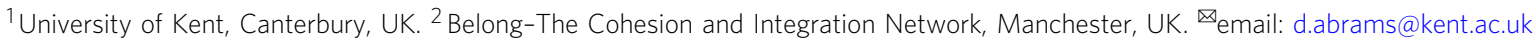




\section{Introduction}

$t$ the time of writing, the coronavirus pandemic has claimed over 3 million lives globally. In the UK alone, at least 127,000 lives were lost. If the crisis is primarily a health crisis, it has also proved to be a political one. Indeed, the urgent and global nature of the pandemic has forced governments worldwide to take action and impose a wide range of measures on their population, often impeding constitutional rights and individual freedoms under the State of Emergency. The pandemic has hence tested the relationships between citizens and governments, sometimes exacerbating political and social tensions.

In this context, political trust has emerged as a key factor in people's relation to the state, their acceptance of governmental measures, and ultimately their compliance with many restrictions. In the past year, a considerable amount of research has shown that political trust was positively associated with compliance with COVID-19 government restrictions (see e.g., Devine et al., 2020, for an early review of the literature). Most of this research has focused on measures of political trust at single points in time, providing snapshots of the situation but not addressing how political trust might have changed throughout the crisis. Moreover, research tracking changes in political trust often relies on yearly or even less-frequent surveys (e.g., Pew Research Center, General Social Survey, European Social Survey; see Citrin and Stoker, 2018). These can identify trends over the years and decades, but they do not capture more granular, shorter-term, changes in trust. Given that political trust can move quite quickly in times of crisis (Hasel, 2013; Hetherington and Nelson, 2003; Hunt et al., 1999), and given the rapid political responses to changing COVID-19 rates, it is valuable to understand how political trust is affected in a more compressed and dynamic timeframe.

The present paper integrates multiple sources of quantitative evidence to establish the progression in levels of political trust at a more granular level over the course of 2020. Taken together, and in light of previous theory and findings, this survey evidence can be used to consider how levels of trust change in response to national events, their natural trajectory over time, and what implications these changes in the trust may have for future management of the coronavirus and other pandemic events.

\section{Political trust}

Political trust refers to the confidence people have in their government, and the extent to which they see their government as trustworthy, credible, fair, and competent (Levi and Stoker, 2000). Political trust is an evaluative attitude held by a citizen towards their political system or agents, with several components contributing to the overall evaluation, notably technical competence or success, ethical and fair conduct, and perceived congruence with citizens' best interest (Bertsou, 2019; see also Citrin and Stoker, 2018). Relatedly, it is rather unsurprising to observe a link between political trust and political partisanship, trust usually being higher for citizens sharing a common identity (Tyler and Degoey, 1995) and party affiliation with the leadership (e.g., Hooghe and Oser, 2017; Pew Research Center, 2010). However, political trust cannot be reduced to partisanship. Partisans may become disappointed with their government's performance or latest policy decisions; and contrariwise, nonpartisans may still judge that their government acts in a competent or ethical manner even if they disagree on specific policy decisions (Citrin and Stoker, 2018).

Historically, political institutions and Members of Parliament or similar representatives, tend to be distrusted rather than trusted (Full Fact, 2019). People in the UK typically feel unrepresented by the UK government in Westminster (Electoral
Reform Society, 2019). One reason, as stated above, is that citizens who do not share a common social identity with a government (different party affiliation) tend to trust it less so that a significant portion of the population is likely to distrust any contemporaneous government. However, political trust has also generally been on the decline in some countries for several decades (including the USA and the UK, Curtice et al., 2020), which scholars have linked to the resurgence of political scandals and the prominence of cynical messages about politicians in mainstream media (Citrin and Stoker, 2018; Levi and Stoker, 2000).

\section{Political trust during crises}

Several psychological mechanisms suggest that in periods of crisis, people look to their government and political leadership for guidance and this, temporarily, increases political trust. The first mechanism relates to a human need for control in an uncertain and ever-changing world. To address this fundamental need, individuals develop subjective impressions of control that do not necessarily correspond to an objective reality (Langer, 1975) but can be psychologically sufficient to restore a sense of control-regardless of their actual degree of control on the situation (Dubois, 1987). Importantly, subjective control includes perceptions of both one's own control and that of close others. In this respect, especially during a global crisis when individual means of action are drastically reduced, feeling psychologically close to a leadership figure-perceived as exerting greater control over the situation (Kay et al., 2008) - can help indirectly restoring people's subjective sense of control (Rothbaum et al., 1982). Consequently, people's need for control is met vicariously by the authorities, and this bolsters people's trust in those authorities' capacities and competence to manage the situation (Albertson and Gadarian, 2015).

A second mechanism is that being collectively affected by a common situation generates a feeling of common fate, which reinforces favourable impressions of other members of the group (Rabbie and Horwitz, 1969). This increases trust and cooperation within the group to address the crisis situation (Kramer and Brewer, 1984), which benefits the group leaders just as well as other members (see also Abrams et al., 2018; Hogg, 2001).

Finally, in challenging times individuals tend to seek social support from close others (Collins and Feeney, 2000). Scholars have suggested that in a similar manner, citizens seek the support of authority figures (or leaders) in times of crisis, just as children would turn to their parents (Kets de Vries et al., 2004). As Hasel puts it, individuals "look to their leaders for actions, solutions to the crisis, and for explanations that will help them to interpret and respond to perceived threats and uncertainties" (Hasel, 2013, p. 265).

Outside of psychology, this effect has mostly been studied as a phenomenon of 'rallying-round-the-flag'. First proposed by Mueller (1970), the rally effect represents "the sudden and substantial increase in public approval of the president [or other political leading figure] that occurs in response to certain kinds of dramatic international events involving the country" (Hetherington and Nelson, 2003). Accordingly, a specific set of causes seems necessary for the rally effect to appear: the emergence of a (1) international event that (2) directly involves one's country and (3) is "specific, dramatic, and sharply focused" (Hetherington and Nelson, 2003; Lee, 1977; Mueller, 1970). Congruent with the above-suggested mechanisms, explanations for the rally effect include that "when feeling vulnerable and under threat, citizens put their trust in political leaders and authorities to protect them" and that "patriotic feelings led the public to view the incumbent 
as the focus of national unity, leading to greater support as citizens set aside their partisan biases" (Jennings, 2020).

Consequently, in periods of crisis people more readily accept various measures from political leaders, including stringent restrictions on their personal freedom. Evidence also shows that people prefer more authoritative and action-focused leadership, much more so than in 'normal' times (Hunt et al., 1999).

Yet, the question remains as to how enduring the rally effect might be. During a prolonged crisis, the public is likely to start scrutinising the actions of the government more closely and evaluate how well or badly these have helped to address the crisis. Past work has noted that presidential approval, surging in the aftermath of a crisis, most often dropped to the pre-crisis level in a matter of months (Mueller, 1970). It also seems that the reluctance from the opposition to criticise national leadership decisions helps sustain the rally effect (Hetherington and Nelson, 2003). Hence, one can expect the crisis-induced boost in political trust to last longer when the leadership actions are seemingly appropriate and efficient, both in terms of objective performance and subjective perception by the public, relayed by the opposition and the media.

Why does political trust matter during the COVID-19 crisis? The prior evidence suggests that political trust should show some marked changes during the first months of the COVID-19 pandemic; but how much should these changes matter? The literature has documented a number of consequences of political trust for citizens' behaviour, including institutionalised (e.g., voting, Hooghe and Marien, 2013) and non-institutionalised engagement (e.g., demonstrating, Kaase, 1999; see Citrin and Stoker, 2018; Levi and Stoker, 2000, for reviews). Particularly relevant for the COVID-19 pandemic are earlier findings that individuals who trust their political institutions are more likely to follow rules and regulations imposed by their government (Levi and Stoker, 2000; Marien and Hooghe, 2011), especially amongst individuals who do not perceive regulations to be in their own personal interest (Rudolph and Evans, 2005). Early evidence seemed to confirm that political trust is associated with compliance with different COVID-19 restrictions and guidelines: Several large-scale international surveys found positive associations between political trust at the individual level and the adoption of health-protective behaviour (Han et al., 2021; Pagliaro et al., 2021; see also Devine et al., 2020, for an early review of the literature) and others found the same association at the regional or country-level (Bargain and Aminjonov, 2020; but see Woelfert and Kunst, 2020). Some evidence also indicates that political trust is especially important to motivate compliance amongst people who feel less concerned about the consequences of the pandemic for themselves and others (Lalot et al., 2021).

\section{Overview of the present research}

Considering that political trust can change quickly in times of crisis, and plays a vital role in shaping relations between citizens and the state and influencing the behaviour of the former, we aim here to document the variations in political trust from the UK population during the first year of the COVID-19 pandemic. Public political trust has been measured in different ways, at different times, and by different surveys. Consequently, evidence from different surveys is rarely directly comparable. To our knowledge, there has been no prior effort to integrate numerous sources of survey evidence on trust and distrust during the pandemic. Furthermore, there is no comprehensive account of changes in trust at multiple points within the same 12-month window to document the stability or variability in levels as a more continuous process in the context of the changing features of this national crisis. To address this significant lacuna (multiple sources and multiple time points) we tracked and integrated the forms of political trust and distrust measured most consistently across different social surveys in Great Britain over the course of 2020. This enabled us to provide as robust as possible a map of the evolution of trust across stages of the coronavirus pandemic and to comment on the implications that these trajectories may have for the future.

Forms of political trust. The surveys included in our analyses had predominantly measured three forms of political trust: general trust in the government, trust in national political leadership (i.e., the UK Prime Minister), and trust in the government's endeavour to handle the pandemic. As noted by several scholars, political trust (or distrust) can be directed towards different objects, either the political system in its entirety or specific components of it (e.g., Bertsou, 2019). Over time, (dis)trust seems to spill over from one political object to the others, in a virtuous/ vicious circle dynamic. Indeed, long-lasting dissatisfaction over consecutive leaders is likely to transform into a general distrust of the system (and vice-versa). Yet, specific components of trust might sit at different levels, especially in the case of novel and rapidly changing contexts such as the pandemic, requiring the government to take unprecedent measures and impose new restrictions on its citizens. Accordingly, we chose to examine changes in the three forms of political trust separately.

Political trust, distrust, and mistrust. An ongoing debate in the literature concerns the relationship between political trust and distrust, with strong voices arguing that distrust does not merely represent a lack of trust but forms a distinct and orthogonal concept (Bertsou, 2019). Others have highlighted the differences between distrust and mistrust, the former representing a strong and settled belief in the untrustworthiness of the government and the latter reflecting doubt and scepticism (Citrin and Stoker, 2018). The issue becomes even more complicated when it comes to measurement, with some instruments assessing (lack of) trust and distrust on separate scales, and others assessing them together as the opposite endpoints of a continuum (mistrust hence being represented as the midpoint of the scale). The data considered in the present paper similarly showed some variations in measurement. However, most items adopted the continuum approach-ranging from strong distrust to strong trust. The middle point (when present) was differently labelled as neutral, unsure, or neither trust nor distrust. It, therefore, represented a variety of mixed opinions, but not necessarily mistrust. Consequently, we focused our analyses on the directional points of the scales which we defined as distrust and trust and did not seek to define or interpret responses on the middle point.

Key time points. Based on past literature on political trust and distrust as well as early work in the context of the COVID-19 pandemic, we identified two time points that could prove key in the evolution of trust in the UK during the year 2020. The first was the introduction of the first lockdown in March 2020 (announced by the Prime Minister on 23 March and implemented on $26 \mathrm{March}$ ). As citizens seem to show an appetite for strong leadership measures in times of crisis (Hasel, 2013; Hunt et al., 1999), it seems reasonable to expect that leadership approval and political trust would increase after such strong measure has come into force. Recent data support this view, showing with pre-post comparisons that general trust in government, vote intentions for the leading party, and even satisfaction with democracy increased after the start of a national lockdown across 15 European countries (Bol et al., 2021)-this is 
particularly noteworthy given that lockdown measures often bypassed democratic procedures and severely limited constitutional rights (see also Oude Groeniger et al., 2021). Accordingly, we expected political trust to increase right after the start of the first lockdown in March 2020.

The second key time point in the UK was the so-called Dominic Cummings scandal, which emerged in late May 2020. At the time of the scandal, Dominic Cummings was a senior adviser to the Prime Minister. On 22 May 2020, several British newspapers published details on how Mr. Cummings had breached lockdown rules, travelling more than $400 \mathrm{~km}(260$ miles) to a family estate with his child and wife who had COVID19 symptoms (Weaver, 2020). Cummings neither apologised nor resigned after the case was made public and went as far as saying he did not regret his actions. He was largely defended in his position by the UK government, which triggered public outrage and media condemnation. Scholars suggested that this breach of the rules, failure to apologise, and support by the government, undermined the credibility of government guidance around COVID-19 (Mahase, 2020) and damaged public confidence (Fancourt et al., 2020). With respect to these early findings, we also expected political trust to decrease following the media coverage of the Cummings scandal from 22 May 2020.

These two key time points served as a basis to determine which statistical models were likely to best fit the data. Specifically, we expected political trust to show a nonlinear effect across all of 2020, with an increase appearing around the time of the introduction of the first lockdown (March 2020), relative stabilisation of higher trust from March to May (i.e., rallyround-the-flag), then a decrease of trust from May onwards, following the Dominic Cummings scandal. To test this latter effect more specifically, we also tested for a linear trend starting from May 2020 onwards.

\section{Methods}

Data collection. To identify evidence from relevant social surveys we began by contacting as many survey research organisations and research funders as we were able to. We also scanned news reports and other sources to identify all possible candidates that could provide data sources for this review. Some organisations that held potentially relevant data were not in a position to release it to us for inclusion. However, we believe that the range of sources that we were able to include was reasonably comprehensive so that any data sources that were missed would be unlikely to alter the conclusions of our analysis. Once the data sources had been identified we examined all relevant measures of trust that had been measured within the UK spanning the period December 2019 to October 2020. We identified 18 different survey sources with relevant measures (see survey details in Appendix 1).

Specifically and as briefly outlined above, we identified measures of general political trust (i.e., level of trust that respondents generically have in the government; example item: "Could you indicate the amount of trust you have in the government?"), trust in national political leadership (i.e., specific trust in the UK Prime Minister, Boris Johnson; example item: "How much do you think Boris Johnson is a leader that can be trusted?"), and trust in the government's effort to handle the coronavirus outbreak (example item: "To what extent do you think the UK Government is handling the COVID-19 response well or badly?"). Whereas the general political trust measures implicitly focus on a basket of aspects such as moral probity, benign intent and so forth, these more specific measures of COVID-19 related trust focus on the competence and technical capacity of government. While one might expect the general and specific measures to be closely related it is plausible that judgements of competence might reflect and respond to external events differently (see Bertsou, 2019; Citrin and Stoker, 2018). Across surveys and time, the evidence involves nearly a quarter of a million $(240,517)$ respondents.

Statistical analysis. The various surveys employed differing methodology and sampling techniques, ranging from longitudinal representative samples to snapshot convenience samples. Different surveys were fielded at different time points and the data collection periods for some surveys spanned more than one week. Before turning to the main analyses, we, therefore, conducted a feasibility analysis on a new small sample of British participants $(N=400)$. This analysis established the set of items measuring general political trust, trust in national leadership, and COVID-19 related trust that could meaningfully be compared across surveys. It also established a procedure for scoring these in ways that maximised comparability of estimates of endorsement of each valence of response. In summary, we plot the percentage of respondents who expressed either trust or distrust on whichever measure was used in each survey (Citrin and Stoker, 2018). All details are reported in Appendix 2 and a full list of the different items used across surveys is available in Appendix 3.

Where possible, for each survey source, data were logged by a week of the year. Where data from multiple surveys were available for the same week, scores were aggregated (weighted by sample size). We noted low sample sizes for some weeks within some surveys. To avoid the use of potentially unreliable data, data were included in the analyses only when (across all sources) data were available for 100 or more respondents for any given week. For all measures, we document both levels of trust and levels of distrust.

For each measure, we fit several polynomial regression models to the data to assess the best fitting trend across time. A higher degree polynomial was included in the final regression model based on significant improvement of model fit. Firstly, for each measure we fit the regression model across the entire December 2019-October 2020 time span. Secondly, based on expectations and evidence that public trust declined following Dominic Cummings' breaking of lockdown rules in May 2020, we additionally fit regression models for each measure assessing the trends in trust and distrust specifically from May 2020October 2020. In doing so, we extend previous research by establishing whether this identified decline in trust is linear or curvilinear.

\section{Results}

General political trust. As displayed in Fig. 1, levels of general political trust in the UK were low immediately following the highly divisive, Brexit-focused, General Election (December 2019). At that time only $20 \%$ of respondents trusted the Government, and a clear majority (60\%) distrusted the Government. As lockdown commenced (23 March 2020) there was a slight elevation in trust, accompanied by a clear reduction of distrust, which fluctuated between 25 and 35\% during the initial months of the lockdown. At the start of May 2020, for the first and only time during 2020, the percentage of respondents that trusted the government exceeded the percentage that distrusted the government.

The Dominic Cummings scandal was then reported by the press on 22 May and there followed a sharp increase in general political distrust in the month of May, reaching $65 \%$ by the end of June 2020. From that point onwards, levels of general political trust remained relatively stable, but an increased proportion of respondents shifted from neutrality to distrust. With slight 


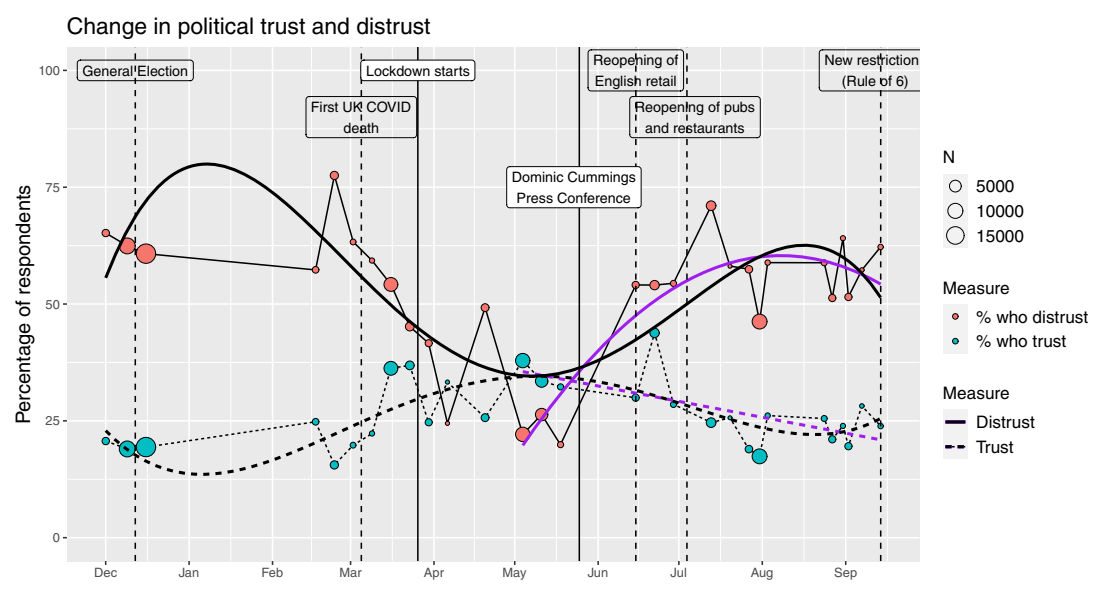

Fig. 1 Change in political trust and distrust from December 2019 to October 2020. Notes. Trend lines for the full-time period are displayed in black and trend lines for the post-Cummings period of May 2020 onwards are displayed in purple. The key events for the first UK lockdown and the Dominic Cummings scandal are displayed. Other labelled events are to provide additional contextual information but are not necessarily related to changes in trust.

variations, levels of political trust and distrust reverted to the prepandemic levels observed in February 2020 such that by September 2020, only $23 \%$ of respondents indicated trust in government.

Considering trust and distrust separately (see Fig. 1), across the entire year the relationship between time and trust is best fit by a quartic polynomial model, $F(4,24)=6.03, p=.002, R^{2}=.50$, $y=26.18+2.64 x-19.92 x^{2}-4.33 x^{3}+15.85 x^{4}$. Inclusion of the quartic term significantly improved the model fit relative to the cubic, $\Delta R^{2}=.19, F(1,24)=8.99, p=.006$, quadratic, $\Delta R^{2}=.20$, $F(2,24)=4.83, p=.017$, and linear models, $\Delta R^{2}=.49, F(3$, $24)=7.96, p<.001$. The quartic and quadratic coefficients were significant in the final model $\left(p_{\mathrm{s}}<.01\right)$.

For political distrust, a quartic polynomial model also provided the best fit, $F(4,24)=6.90, p<.001, R^{2}=.54, y=52.71-1.97 x+$ $37.90 x^{2}+6.96 x^{3}-38.57 x^{4}$. Inclusion of the quartic term significantly improved the model fit relative to the cubic, $\Delta R^{2}=.27$, $F(1,24)=13.80, p=.001$, quadratic, $\Delta R^{2}=.28, F(2,24)=7.13$, $p=.004$, and linear models, $\Delta R^{2}=.53, F(3,24)=9.19, p<.001$. The quartic and quadratic coefficients were significant in the final model $\left(p_{\mathrm{s}}=.001\right)$. The quartic models for trust and distrust indicate that a curvilinear trend with three turning points provided the best fit to the data. As seen in Fig. 1, these turning points are visibly defined by the rising level of trust (and falling level of distrust) from December 2019 to March 2020, a reverse from increasing to decreasing levels of trust, and from decreasing to increasing levels of distrust, in the latter weeks of May 2020, and the slight increase in trust and decrease in distrust at the end of September 2020.

Focusing only on the post-Cummings period, from May 2020 onwards, trust is best fit by a linear model, $F(1,15)=13.14$, $p=.002, R^{2}=.47, y=27.11-18.86 x$. Distrust is fit by a quadratic polynomial model, $F(2,14)=24.58, \quad p<.001$, $R^{2}=.78, y=51.05+43.06 x-28.40 x^{2}$. The addition of the quadratic term provided a significantly better fit than the linear model, $\Delta R^{2}=.24, F(1,14)=14.90, p=.002$. Both linear and quadratic coefficients were significant in the final model $\left(p_{\mathrm{s}}<.01\right)$. The quadratic model indicates that a curvilinear trend with one turning point provided the best fit to the distrust data in the postCummings period. In other words, from May 2020 trust has decreased linearly, while distrust rose from May until August 2020 , at which point it remained stable with a slight decrease in September.
Trust in national political leadership. Levels of trust in UK Prime Minister Boris Johnson were at a low point following the 2019 General Election, with only $28 \%$ of respondents indicating they trusted Boris Johnson at the end of December, and 57\% indicating they distrusted him (see Fig. 2). However, following the introduction of the first lockdown in March, trust had risen substantially to $49 \%$. Levels of distrust concomitantly had fallen to $14 \%$. This was the only time point during 2020 at which levels of trust surpassed those of distrust-showing a typical rallyround-the-flag effect. From April onwards there was a general decline in trust in Boris Johnson, accompanied by a matching incline in distrust throughout the rest of the year. By October 2020, levels of trust in Boris Johnson had reverted to the levels observed at the beginning of the year, with $24 \%$ of respondents indicating they trusted Boris Johnson and 57\% indicating they distrusted him.

A quartic polynomial model provided a significant fit for trust, $F(4,21)=6.77, p=.001, R^{2}=.56, y=29.76-12.70 x-21.79 x^{2}+$ $6.10 x^{3}+14.96 x^{4}$. Inclusion of the quartic term significantly improved model fit relative to the cubic, $\Delta R^{2}=.14, F(1$, $21)=6.76, p=.017$, quadratic $, \Delta R^{2}=.16, \quad F(2,21)=3.94$, $p=.035$, and linear models, $\Delta R^{2}=.46, \quad F(3,21)=7.41$, $p=.001$. Quartic, quadratic and linear coefficients were significant in the final model $\left(p_{\mathrm{s}}<.05\right)$. The quartic model indicates that a curvilinear trend with three turning points best fit the trust data, as shown in Fig. 2. As with the general political trust measure, these turning points are characterised by increasing levels of trust from December 2019 to March 2020, decreased levels from May 2020, and slightly increased levels in September 2020.

For distrust, a quadratic model provided the best fit, $F(2$, $23)=6.17, p=.007, R^{2}=.35, y=49.86+20.41 x+33.81 x^{2}$. The inclusion of the quadratic term provided a significantly better fit than the linear model, $\Delta R^{2}=.26, F(1,23)=9.04, p=.006$. Only the quadratic coefficient was significant in the final model $(p=.006)$. The quadratic model indicates that a curvilinear trend with one turning point provided the best fit to the data, characterised by a reversal from decreasing to increasing levels of distrust between April and May 2020.

From May 2020 onwards, a linear line provided the best fit for trust in Boris Johnson, $F(1,13)=14.74, p=.002, R^{2}=.53$, $y=26.92-14.43 x$. For distrust, a quadratic model, $F(2$, $12)=11.84, \quad p=.001, \quad R^{2}=.66, \quad y=55.32+15.83 x-8.45 x^{2}$, 


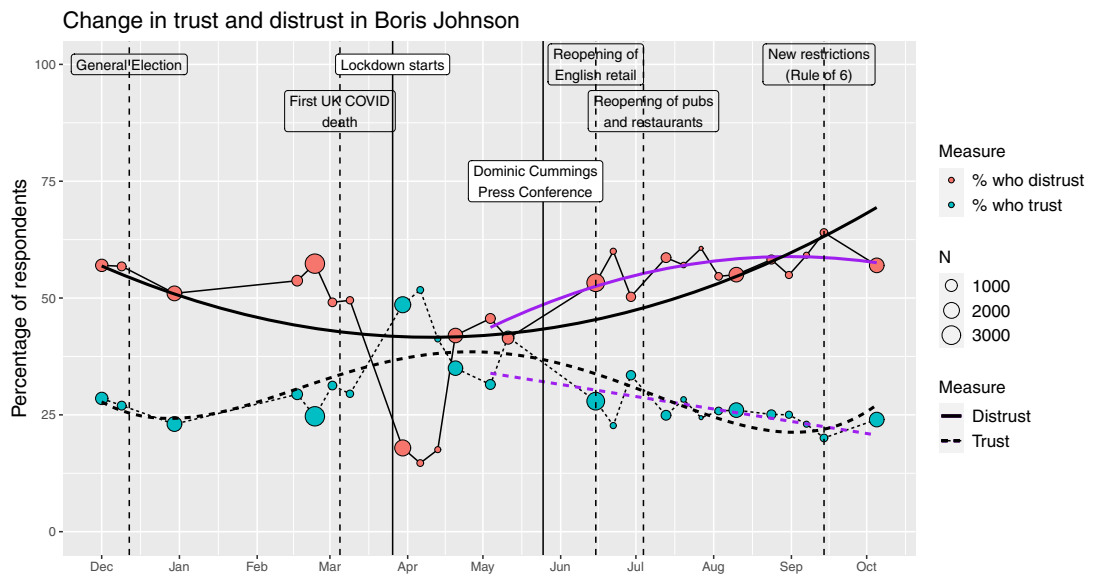

Fig. 2 Change in trust and distrust in Boris Johnson from December 2019 to October 2020. Notes. Trend lines for the full-time period are displayed in black and trend lines for the post-Cummings period of May 2020 onwards are displayed in purple. The key events for the first UK lockdown and the Dominic Cummings scandal are displayed. Other labelled events are to provide additional contextual information but are not necessarily related to changes in trust.

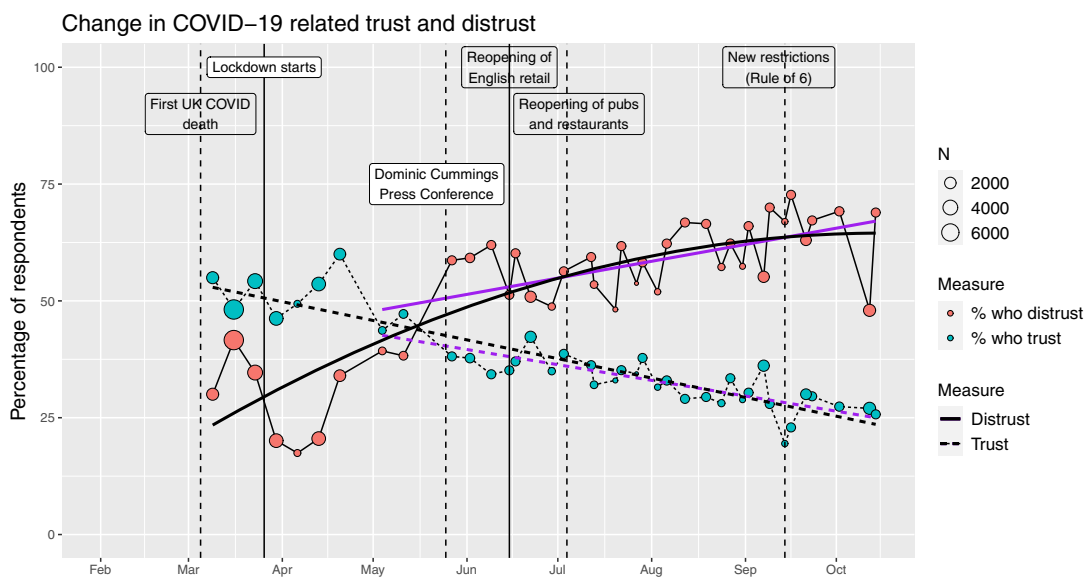

Fig. 3 Change in COVID-19 related trust and distrust from March to October 2020. Notes. Trend lines for the full-time period are displayed in black and trend lines for the post-Cummings period of May 2020 onwards are displayed in purple. The key events for the first UK lockdown and the Dominic Cummings scandal are displayed. Other labelled events are to provide additional contextual information but are not necessarily related to changes in trust.

continued to provide a better fit than a linear model, $\Delta R^{2}=.14$, $F(1,12)=5.25, p=.041$. Both linear and quadratic coefficients in the final model were significant $\left(p_{\mathrm{s}}<.05\right)$. These models suggest that trust in national political leadership linearly fell from May onwards, whereas a curvilinear trend with one turning point best fit distrust in national political leadership. This was characterised by the stabilising and slightly decreasing levels of distrust occurring between September and October 2020.

COVID-19 related trust. The first available measures of COVID19 related trust in the UK (trust specifically in the government's handling of the pandemic) date from March 2020, immediately after the first confirmed COVID-19 death in the country. From that point on there were growing calls by scientists, opposition parties and media commentators to introduce a lockdown. ${ }^{1}$

As shown in Fig. 3, levels of trust in COVID-19 measures were initially high and fluctuated between $48 \%$ and a peak of $60 \%$ during the first month of lockdown (April). However, in line with general political trust, there was a gradual linear decline in COVID-19 related trust from May 2020 onwards, with small fluctuations but a general downward trend for the rest of the year. By October 2020, levels of COVID-19 related trust had fallen to $25 \%$.
Distrust in COVID measures was at its minimum immediately following the lockdown in March but then showed a linear rise from May onwards, again with some fluctuations. Distrust began to level out from September and had reached $68 \%$ in October 2020. Notably, the fluctuation in distrust is much larger than that of trust, suggesting that people feel more consistent in their level of trust, with distrust being more volatile.

A linear model provided the best fit for COVID-19 related trust, $F(1,38)=171.00, p<.001, R^{2}=.82, y=36.35-52.77 x$. This indicates that COVID-19 related trust linearly fell from March 2020 to October 2020. For distrust, a quadratic polynomial model provided the best fit, $F(2,37)=46.5, p<.001, R^{2}=.72$, $y=53.25+73.22 x-19.73 x^{2}$. Inclusion of the quadratic term provided a significantly better fit than the linear model, $\Delta R^{2}=.05, F(1,37)=6.29, p=.017$. Both linear and quadratic coefficients were significant in the final model $\left(p_{\mathrm{s}}<.01\right)$. The quadratic model suggests that a curvilinear trend with one turning point best fit the COVID-19 related distrust data, characterised by a linear incline that begins to stabilise in July and slightly decrease in October 2020.

From May onwards, a linear line continued to provide the best fit for COVID-19 related trust, $F(1,31)=70.28, p<.001$, 
$R^{2}=.69, y=32.95-27.51 x, p<.001$. For distrust, a linear line provided the best fit from May onwards, $F(1,31)=19.25$, $p<.001, R^{2}=.38, y=58.52+29.54 x, p<.001$. These models suggest that COVID-19 related trust linearly fell from May 2020, whilst COVID-19 related distrust linearly increased.

\section{Discussion}

With data from over 240,000 respondents, we have documented the trends in political trust and distrust across the first year of the coronavirus pandemic in the UK. In line with previous research (e.g., Full Fact, 2019), pre-COVID general political trust levels in the UK were generally low, perhaps entrenched through the years of the EU referendum and subsequent Brexit. Yet this situation is neither inevitable nor permanent. In line with past research and theory on trust in response to crises and more specifically the rally-round-the-flag effect, all three measures of trust revealed substantial rises at the onset of the UK's lockdown response to the pandemic (see Bol et al. 2021; Hasel, 2013; Oude Groeniger et al., 2021). Across measures, methods and samples, levels of trust remained high in the month period following lockdown. However, they then revealed a gradual, and often linear, decline for the remainder of the year.

Reinforcing others' findings, we also found evidence that the Dominic Cummings' scandal might have precipitated the decline in trust from May 2020 onwards (Fancourt et al., 2020; Mahase, 2020). The three measures (general political trust, trust in national political leadership, and COVID-19 specific trust) followed the same upwards then downwards trend. This supports the view that specific forms of trust (and distrust), although conceptually distinct, show a spill-over effect, feeding into one another (Bertsou, 2019). Yet, there were also some notable differences in the exact timing of the changes across measures. Specifically, it was trust in national political leadership (in Prime Minister Boris Johnson) that showed the sharpest increase following the introduction of lockdown, which suggests that the rally-round-the-flag effect manifests itself first at the level of the leadership figure (considered elsewhere as presidential approval or popularity, e.g., Lee, 1977; Mueller, 1970) before translating into an increase in general political trust (Hetherington and Nelson, 2003).

In sum, the data supported the notion of people 'rallying round' the leadership figure in times of crisis, granting trust and supporting strong governmental measures. Yet, it also showed that this coming-together effect was short-lived in the UK, likely precipitated by the persisting nature of the pandemic with cases and deaths increasing with time, active criticism of government decisions by the opposition and the media, and at one point the breach of rules by a prominent senior political figure-the Dominic Cummings scandal. It is unlikely that the specific trust level was determined solely by that episode, but the change in the trajectory of trust is consistent with other evidence on people's reactions more generally when leaders breach not just legal but moral contracts with their groups (Abrams et al., 2014). Research on leadership shows that people are more responsive to and more supportive of leaders that they perceive to be representative of the group (e.g., the country), embodying its values and interests (Hogg, 2001). Events and behaviour that imply 'one rule for them, another rule for us' therefore inevitably present a barrier to trust in government.

Implications. Although the wider and more protracted impacts of this pandemic may be yet to reveal themselves (British Academy, 2021a, 2021b), the initial trust dividend that may have facilitated collective resilience through the first lockdown appears to have all but evaporated. Initial confirmation of predictions derived from past theory and research on responses to crises is scientifically reassuring. But this evidence points to the scale of the ensuing challenge posed by the waning of the crisis-induced trust that people placed in the government at the start of the pandemic. For example, it seems that scope to regenerate trust in the face of a further crisis (e.g., new variants of coronavirus) or protracted restrictions (e.g., while awaiting deployment of vaccines), or new emergencies, may be weakened if people feel 'once bitten twice shy' when they reflect on 2020 .

Beyond the immediate problem of re-securing trust, the short time span of enhanced trust has wider implications for the design and implementation of governmental responses to crisis events. Research has long shown that trust positively predicts compliance with government guidelines and restrictions (Citrin and Stoker, 2018; Levi and Stoker, 2000; Marien and Hooghe, 2011; Rudolph and Evans, 2005; Tyler, 2001, 2006) including those relating to coronavirus (Bargain and Aminjonov, 2020; Devine et al., 2020; Han et al., 2021; Lalot, Heering, et al., 2021; Pagliaro et al., 2021; Travaglino and Moon, 2021), as well as previous pandemics (Blair et al., 2017; see also Siegrist and Zingg, 2014)-although some have noted that trust can backfire if it leads to citizens to underestimate the actual level of risks (Wong and Jensen, 2020). It hence seems that heightened political trust (combined with a reasonable degree of concern or realism in the face of the risks, Lalot et al., 2021) is desirable for all parties involved. Beyond compliance with short-term restrictions, trust is likely to play a key role in citizens' support for/opposition to various other measures as countries work their way out of the pandemic. Personal vaccination intentions (or "vaccine hesitancy") are likely to be impacted by trust (Lalot et al., 2021) and so are attitudes towards vaccine (or immunity) passports (Abrams et al., 2021).

The question then arises of whether that initially elevated trust could have been better entrained and used, and whether there are specific ways in which that might be achieved in the event of a future pandemic or other crisis. If such events create a narrow window in which to capitalise on elevated public trust, the opportunity needs to be seized quickly and with a well-prepared plan of action (Baum et al., 2009; Siegrist and Zingg, 2014). Whether by accident, design or scheduling, changes of government or leadership may be prime opportunities to revitalise such trust and bolster the efficacy of public health initiatives.

It is possible that trust is highly labile in response to particular events or information, and so could go up as rapidly as it goes down. Alternatively, given the historical ebbs and flows in trust in response to crises, it could be argued that short-term peaks of crisis-induced trust are predictable and inevitable but are well beyond any political or policy leverage. Such peaks may simply reflect people's natural needs and motivation for certainty and structure during crises. As things become clearer or more predictable people's need to trust authority wanes. But even if dividends in the political trust are short-lived, the case for effective government action to respond to people's underlying needs and motivations remains clear. For example, had the UK government delayed lockdown or continued with a more laissezfaire approach during April 2020, we might have witnessed both higher infection rates and also a much more rapid loss of trust that would have compounded subsequent challenges of securing and coordinating public cooperation as the pandemic re-ignited later in the year.

Limitations and future directions. In the present analysis we sought to capture trust and distrust levels across multiple surveys that used different data collection methods and different measurement methods, such as item wording and scale ranges. We first conducted independent analyses to ensure comparability 
across measures, and this resulted in a simplified data structure (see Appendices 2 and 3). We recognise that this simplification increases the unexplained variability but factor analytic assessment does provide confidence that interpretation of these different data sources is not compromised by the wording and scalar differences in measurement. We additionally note that, due to the variability in the labelling or even presence of a 'neutral' scale point between surveys, our analysis focuses specifically on trust and distrust. Consequently, our analysis cannot speak with precision to whether changes in average levels of trust or distrust arise because individuals shift directly between trust or distrust, or because they have shifted from neutral positions.

Trust may be attached differently to different levels of political representation (e.g., local versus national). The available data enabled us to assess only the three forms that had been measured consistently across sources. These encompass the most relevant domains of political trust at a general level, and therefore embody but might mask what might be inferred from more nuanced measures. Specific details of trust in particular government institutions, in health authorities or in local leadership might be reflected in particular spheres that reveal greater or lesser influence and compliance. Unfortunately, these specificities have been measured infrequently or only by few surveys.

Finally, although the present data focus on trust in the UK and will reflect a timeline of events that is specific to the UK, similar social and psychological processes should underlie changes in levels of trust in other countries and contexts in response to their own handling of the pandemic. The UK's pre-pandemic levels of political trust were already far from optimal following the culmination of an extremely rancorous period in the UK's political and economic history, namely a decade of austerity followed by Brexit. Similar conditions prevailed in other countries but for different reasons and point to the broader question of whether and how such low levels of political trust can be sufficient for effective government.

\section{Conclusions}

Beyond the most immediate challenge of distributing vaccines, many countries face substantial difficulties ahead in other spheres such as rising unemployment and homelessness, tax rises and longer-term damage to health and education (British Academy, 2021a, 2021b). If these are accompanied by a continuing downward trajectory in political trust, there may be a point at which the absence of trust itself constitutes a crisis. Government and local authorities will need to communicate regularly and effectively to address people's concerns and uncertainties in these areas. Trust plays a critical role because effective communication depends on the relationship between senders and receivers. It is likely to be achievable only if people have sufficient trust in the political system as a whole and leadership in particular. The present evidence shows there are circumstances and conditions in which political trust rapidly increases. This suggests that opportunities remain open to build political trust at multiple levels, from national to hyperlocal, as part of efforts to respond to the difficult years ahead.

\section{Data availability}

The datasets generated analysed during this study are not publicly available given that not all organisations gave their consent for public use of the data they shared with the authors. Data are available from the corresponding author on reasonable request.

Received: 9 February 2021; Accepted: 22 June 2021; Published online: 09 July 2021

\section{Note}

1 See for example the petition demanding the implementation of a UK lockdown, which gathered 400,000 signatures in just a few hours (https://petition.parliament.uk/ petitions/301397).

\section{References}

Abrams D, Lalot F, Broadwood J, Davies Hayon K (2021) How accepting is the British public of COVID-19 vaccine passports, and why? Belong-The Cohesion and Integration Network. Retrieved April 2021 from https:// www.belongnetwork.co.uk/resources/how-accepting-is-the-british-public-ofcovid-19-vaccine-passports-and-why

Abrams D, Travaglino GA, Marques JM, Pinto I, Levine JM (2018) Deviance credit: tolerance of deviant ingroup leaders is mediated by their accrual of prototypicality and conferral of their right to be supported. J Social Issues 74 (1):36-55. https://doi.org/10.1111/josi.12255

Abrams D, Travaglino GA, Randsley de Moura G, May PJ (2014) A step too far? Leader racism inhibits transgression credit. Eur J Soc Psychol 44:730-735. https://doi.org/10.1002/ejsp.2063

Albertson B, Gadarian SK (2015) Anxious politics: democratic citizenship in a threatening world. Cambridge University Press

Bargain O, Aminjonov U (2020) Trust and compliance to public health policies in times of COVID-19. J Public Econ 192:104316. https://doi.org/10.1016/j. jpubeco.2020.104316

Baum NM, Jacobson PD, Goold SD (2009) "Listen to the people": public deliberation about social distancing measures in a pandemic. Am J Bioethics 9 (11):4-14. https://doi.org/10.1080/15265160903197531

Bertsou E (2019) Rethinking political distrust. Eur Polit Sci Rev 11(2):213-230 https://doi.org/10.1017/S1755773919000080

Blair RA, Morse BS, Tsai LL (2017) Public health and public trust: survey evidence from the Ebola Virus Disease epidemic in Liberia. Soc Sci Med 172:89-97. https://doi.org/10.1016/j.socscimed.2016.11.016

Bol D, Giani M, Blais A, Loewen PJ (2021) The effect of COVID-19 lockdowns on political support: some good news for democracy? Eur J Polit Res 60 (2):497-505. https://doi.org/10.1111/1475-6765.12401

British Academy (2021a) The COVID Decade: understanding the long-term societal impacts of COVID-19. The British Academy. https://www. thebritishacademy.ac.uk/documents/3238/COVID-decade-understandinglong-term-societal-impacts-COVID-19.pdf

British Academy (2021b) Shaping the COVID Decade: addressing the long-term societal impacts of COVID-19. The British Academy. https://www. thebritishacademy.ac.uk/documents/3239/Shaping-COVID-decadeaddressing-long-term-societal-impacts-COVID-19.pdf

Citrin J, Stoker L (2018) Political trust in a cynical age. Ann Rev Polit Sci 21 (1):49-70. https://doi.org/10.1146/annurev-polisci-050316-092550

Collins NL, Feeney BC (2000) A safe haven: an attachment theory perspective on support seeking and caregiving in intimate relationships. J Personal Soc Psychol 78(6):1053-1073. https://doi.org/10.1037//0022-3514.78.6.1053

Curtice J, Abrams D, Jessop C (2020) Coronavirus and Public Attitudes: Plus ça change?. NatCen Social Research. https://natcen.ac.uk/media/1989002/ Coronavirus-and-public-attitudes.pdf

Devine D, Gaskell J, Jennings W, Stoker G (2020) Trust and the coronavirus pandemic: What are the consequences of and for trust? An early review of the literature. Polit Stud Rev 1478929920948684. https://doi.org/10.1177/ 1478929920948684

Dubois N (1987) La psychologie du contrôle: les croyances internes et externes. Presses Universitaires de Grenoble

Electoral Reform Society (2019) Ending the politics of division-how we can build a new democracy. https://www.electoral-reform.org.uk/westminster-beyondbrexit

Fancourt D, Steptoe A, Wright L (2020) The Cummings effect: politics, trust, and behaviours during the COVID-19 pandemic. Lancet 396(10249):464-465. https://doi.org/10.1016/S0140-6736(20)31690-1

Full Fact (2019) Political trust in the UK. https://fullfact.org/media/uploads/ political-trust-in-the-uk.pdf

Han Q, Zheng B, Cristea M, Agostini M, Belanger JJ, Gutzkow B, Kreienkamp J, Leander NP (2021) Trust in government regarding COVID-19 and its associations with preventive health behaviour and prosocial behaviour during the pandemic: a cross-sectional and longitudinal study. Psychol Med 1-32. https://doi.org/10.1017/S0033291721001306

Hasel MC (2013) A question of context: the influence of trust on leadership effectiveness during crisis. Management 16(3):264-293. https://doi.org/ $10.3917 /$ mana.163.0264

Hetherington MJ, Nelson M (2003) Anatomy of a rally effect: George W. Bush and the war on terrorism. Polit Sci Politics 36(1):37-42. https://doi.org/10.1017/ S1049096503001665

Hogg MA (2001) A social identity theory of leadership. Personal Soc Psychol Rev 5(3):184-200. https://doi.org/10.1207/S15327957PSPR0503_1 
Hooghe M, Marien S (2013) A comparative analysis of the relation between political trust and forms of political participation in Europe. Eur Societ 15(1):131-152. https://doi.org/10.1080/14616696.2012.692807

Hooghe M, Oser J (2017) Partisan strength, political trust and generalized trust in the United States: an analysis of the General Social Survey, 1972-2014. Soc Sci Res 68:132-146. https://doi.org/10.1016/j.ssresearch.2017.08.005

Hunt JG, Boal KB, Dodge GE (1999) The effects of visionary and crisis-responsive charisma on followers: an experimental examination of two kinds of charismatic leadership. Leadership Quart 10(3):423-448. https://doi.org/10.1016/ S1048-9843(99)00027-2

Jennings W (2020) Covid-19 and the 'rally-round-the-flag' effect. UK in a changing Europe: politics and Society. Retrieved 30 March 2020. https://ukandeu.ac.uk/ covid-19-and-the-rally-round-the-flag-effect

Kaase M (1999) Interpersonal trust, political trust and non-institutionalised political participation in Western Europe. West Eur Politics 22(3):1-21. https:// doi.org/10.1080/01402389908425313

Kay AC, Gaucher D, Napier JL, Callan MJ, Laurin K (2008) God and the government: testing a compensatory control mechanism for the support of external systems. J Personal Social Psychol 95(1):18-35. https://doi.org/ 10.1037/0022-3514.95.1.18

Kets de Vries MFR, Vrignaud P, Florent-Treacy E (2004) The Global Leadership Life Inventory: development and psychometric properties of a 360-degree feedback instrument. Int J Human Resour Manag 15(3):475-492. https://doi. org/10.1080/0958519042000181214

Kramer RM, Brewer MB (1984) Effects of group identity on resource use in a simulated commons dilemma. J Personal Soc Psychol 46(5):1044-1057. https://doi.org/10.1037//0022-3514.46.5.1044

Lalot F, Abrams D, Heering MS, Babaian J, Ozkececi H, Peitz L, Davies Hayon K, Broadwood J (2021) Distrustful complacency and the COVID-19 vaccine: how concern and political trust interact to affect vaccine hesitancy. Manuscript under review

Lalot F, Abrams D, Travaglino GA (2021) Aversion amplification in the emerging COVID-19 pandemic: the impact of political trust and subjective uncertainty on perceived threat. J Commun Appl Soc Psychol 31(2):213-222. https://doi. org/10.1002/casp.2490

Lalot F, Heering MS, Rullo M, Travaglino GA, Abrams D (2021) The dangers of distrustful complacency: low concern and low political trust combine to undermine compliance with governmental restrictions in the emerging COVID-19 pandemic. Group Processes \& Intergroup Relations, OnlineFirst. https://doi.org/10.1177/1368430220967986

Langer EJ (1975) The illusion of control. J Personal Soc Psychol 32(2):311-328. https://doi.org/10.1037/0022-3514.32.2.311

Lee JR (1977) Rallying around the flag: foreign policy events and presidential popularity. President Stud Quart 7(4):252-256

Levi M, Stoker L (2000) Political trust and trustworthiness. Ann Rev Polit Sci 3 (1):475-507. https://doi.org/10.1146/annurev.polisci.3.1.475

Mahase E (2020) Covid-19: UK government's defence of senior aide has damaged public and NHS confidence, say experts. BMJ 369:m2109. https://doi.org/ 10.1136/bmj.m2109

Marien S, Hooghe M (2011) Does political trust matter? An empirical investigation into the relation between political trust and support for law compliance. Eur J Polit Res 50(2):267-291. https://doi.org/10.1111/j.1475-6765.2010.01930.x

Mueller JE (1970) Presidential popularity from Truman to Johnson. Am Polit Sci Rev 64(1):18-34. https://doi.org/10.2307/1955610

Oude Groeniger J, Noordzij K, van der Waal J, de Koster W (2021) Dutch COVID19 lockdown measures increased trust in government and trust in science: a difference-in-differences analysis. Soc Sci Med 275:113819. https://doi.org/ 10.1016/j.socscimed.2021.113819

Pagliaro S, Sacchi S, Pacilli MG, Brambilla M, Lionetti F, Bettache K, Bianchi M, Biella M, Bonnot V, Boza M, Butera F, Ceylan-Batur S, Chong K, Chopova T, Crimston CR, Álvarez B, Cuadrado I, Ellemers N, Formanowicz M, Graupmann V, Gkinopoulos T, Kyung Jeong EH, Jasinskaja-Lahti I, Jetten J, Muhib Bin K, Mao Y, McCoy C, Mehnaz F, Minescu A, Sirlopú D, Simić A, Travaglino G, Uskul AK, Zanetti C, Zinn A, Zubieta E (2021) Trust predicts COVID-19 prescribed and discretionary behavioral intentions in 23 countries. PLoS ONE 16(3):e0248334. https://doi.org/10.1371/journal.pone.0248334

Pew Research Center (2010) Section 1: Trust in Government 1958-2010. Distrust, discontent, anger and partisan rancor. The Pew Research Center. https://www. pewresearch.org/politics/2010/04/18/section-1-trust-in-government-1958-2010
Rabbie JM, Horwitz M (1969) Arousal of ingroup-outgroup bias by a chance win or loss. J Personal Soc Psychol 13(3):269-277. https://doi.org/10.1037/ h0028284

Rothbaum F, Weisz JR, Snyder SS (1982) Changing the world and changing the self: a two-process model of perceived control. J Personal Soc Psychol 42 (1):5-37. https://doi.org/10.1037/0022-3514.42.1.5

Rudolph TJ, Evans J (2005) Political trust, ideology, and public support for government spending. Am J Polit Sci 49(3):660-671. https://doi.org/10.1111/ j.1540-5907.2005.00148.x

Siegrist M, Zingg A (2014) The role of public trust during pandemics: implications for crisis communication. Eur Psychol 19(1):23-32. https://doi.org/10.1027/ 1016-9040/a000169

Travaglino GA, Moon C (2021) Compliance and self-reporting during the COVID19 pandemic: a cross-cultural study of trust and self-conscious emotions in the United States, Italy, and South Korea. Front Psychol 12(684). https://doi. org/10.3389/fpsyg.2021.565845

Tyler TR (2001) Trust and law abidingness: a proactive model of social regulation. Boston University Law Rev 81(2):361-406

Tyler TR (2006) Why people obey the law (2nd edn.) Princeton University Press

Tyler TR, Degoey P (1995) Collective restraint in social dilemmas: procedural justice and social identification effects on support for authorities. J Personal Soc Psychol 69(3):482-497. https://doi.org/10.1037/0022-3514.69.3.482

Weaver M (2020) Pressure on Dominic Cummings to quit over lockdown breach. The Guardian. Retrieved 22 March 2020 from https://www. theguardian.com/politics/2020/may/22/dominic-cummings-durham-tripcoronavirus-lockdown

Woelfert FS, Kunst JR (2020) How political and social trust can impact social distancing practices during COVID-19 in unexpected ways. Front Psychol 11:572966-572966. https://doi.org/10.3389/fpsyg.2020.572966

Wong CML, Jensen O (2020) The paradox of trust: perceived risk and public compliance during the COVID-19 pandemic in Singapore. J Risk Res 23(7-8):1021-1030. https://doi.org/10.1080/13669877.2020.1756386

\section{Acknowledgements}

This work was supported by the British Academy (BA Covid and Society, reference: C + S_UoK, awarded to F. Lalot and D. Abrams) and the Nuffield Foundation (grant number WEL/FR-000022582, awarded to D. Abrams, J. Broadwood, and F. Lalot)

\section{Competing interests}

The authors declare no competing interests.

\section{Additional information}

Supplementary information The online version contains supplementary material available at https://doi.org/10.1057/s41599-021-00850-6.

Correspondence and requests for materials should be addressed to D.A.

Reprints and permission information is available at http://www.nature.com/reprints

Publisher's note Springer Nature remains neutral with regard to jurisdictional claims in published maps and institutional affiliations.

Open Access This article is licensed under a Creative Commons Attribution 4.0 International License, which permits use, sharing, adaptation, distribution and reproduction in any medium or format, as long as you give appropriate credit to the original author(s) and the source, provide a link to the Creative Commons license, and indicate if changes were made. The images or other third party material in this article are included in the article's Creative Commons license, unles indicated otherwise in a credit line to the material. If material is not included in the article's Creative Commons license and your intended use is not permitted by statutory regulation or exceeds the permitted use, you will need to obtain permission directly from the copyright holder. To view a copy of this license, visit http://creativecommons.org/ licenses/by/4.0/

(C) The Author(s) 2021 